\title{
Effects of corrective, therapeutic exercise techniques on adolescent idiopathic scoliosis. A systematic review
}

\author{
Luis Ceballos Laita, Kinesiologist ${ }^{a}$, Cristina Tejedor Cubillo, Kinesiologist ${ }^{b}$, \\ Teresa Mingo Gómez, Ph.D. ${ }^{a}$ and Sandra Jiménez del Barrio, Ph.D. ${ }^{a}$
}

\begin{abstract}
The objective of this study was to determine the effects of corrective, therapeutic exercise techniques on subjects with adolescent idiopathic scoliosis. A systematic review was conducted by searching the Cochrane Library Plus, Pubmed, PEDro, and SCOPUS databases. Studies in patients diagnosed with adolescent idiopathic scoliosis that considered corrective, therapeutic exercise as an independent outcome measure and symptoms, functional capacity, Cobb's angle and/or other angles or body asymmetries as dependent outcome measures were included. A total of 9 controlled clinical trials that carried out corrective, therapeutic exercise were included. Corrective, therapeutic exercise appears to have positive effects by reducing symptoms and improving function, as well as various angles and body asymmetries. However, further studies with better methodological quality are required to confirm these outcomes and determine the best therapeutic exercise intervention.
\end{abstract}

Key words: scoliosis, adolescent, applied kinesiology.

http:/ / dx.doi.org/10.5546/ aap.2018.eng.e582

To cite: Ceballos Laita L, Tejedor Cubillo C, Mingo Gómez T, Jiménez del Barrio S. Effects of corrective, therapeutic exercise techniques on adolescent idiopathic scoliosis. A systematic review. Arch Argent Pediatr 2018;116(4):e582-e589.

a. School Faculty of Physical Therapy, Duques de Soria University Campus, Universidad de Valladolid, Soria, Spain.

b. Independent Physical Therapist.

E-mail address:

Luis Ceballos Laita,

Kinesiologist:

Luis.ceballos@uva.es

Funding:

None.

Conflict of interest:

None.

Received: 11-10-2017

Accepted: 2-19-2018 of these AIS cases progress and may be associated with other anomalies, especially neurological disorders. ${ }^{4}$ Given all these manifestations, the early diagnosis and management are critical for a better quality of life.

The characteristic signs of AIS are chest deformities, protuberances, and asymmetries. ${ }^{5}$ Although it is not the main clinical factor, patients with AIS may have pain; they are more prone to pain when the degree of Cobb's angle is higher. ${ }^{6}$ Studies on AIS prevalence have demonstrated that between $27 \%$ and $59 \%$ of patients suffer pain. 5,7 In addition, it may be associated with other conditions, such as restricted ventilation, respiratory muscle weakness, reduced quality of life, ${ }^{8}$ and even psychological problems. ${ }^{9}$

At present, according to the 2016 AIS consensus, ${ }^{1}$ follow-up and management include observation, bracing or surgery. The Scoliosis Research Society (SRS) suggests bracing for patients with a Cobb's angle greater than $25^{\circ}$. Surgery is indicated for subjects with a Cobb's angle greater than $45^{\circ}-50^{\circ}$. In relation to conservative management, several therapeutic exercise interventions have been proposed for this population; their implementation has been recommended not only for those for whom surgery is not indicated but also in combination with other measures, such as braces. The objective of exercise is to reduce symptoms and improve functional capacity and quality of life. ${ }^{10-15}$ Although braces are mainly used in these patients, the isolated effects of corrective, therapeutic exercise on AIS patients are not clear; ${ }^{1}$ actually, the Scientific Society on Scoliosis 
Orthopaedic Rehabilitation and Treatment (SOSORT) ${ }^{16}$ has shown that the evidence of conservative management in these patients is scarce.

The objective of this study was to determine, through a systematic review, the effects of corrective, therapeutic exercise on patients diagnosed with AIS.

\section{METHODS}

A systematic review was conducted in accordance to the Preferred Reporting Items in Systematic Reviews and Meta-Analyses (PRISMA) Statement. ${ }^{17}$

\section{Eligibility criteria}

The eligibility criteria to select articles were established based on the SOSORT's recommendations: ${ }^{18}$

- Controlled clinical trials (CCTs).

- Specification that sample subjects had been diagnosed with AIS and had a Cobb's angle of $10^{\circ}-45^{\circ}$.

- A sample of pediatric patients according to the regulations of the country where the study is conducted. According to the Spanish Society of Pediatrics, $51.7 \%$ of countries considered that pediatric age covered patients from 0 to 18 years old. ${ }^{19}$

- An intervention based on corrective, therapeutic exercise as an independent outcome measure and a comparison with a placebo or control group or with other nonsurgical techniques.

- At least one of the following dependent outcome measures: symptoms, functional capacity, Cobb's angle and/or other angles or body asymmetries.

Exclusion criteria:

- Any other surgical or brace intervention.

\section{Article search}

CCTs were searched in the following databases recognized by the scientific community: The Cochrane Library Plus, Pubmed (MEDLINE), Physiotherapy Evidence Database (PEDro), and SCOPUS between February and October 2017. Articles in English, French or Spanish were considered for inclusion, and no limits were set on publication dates.

The following Medical Subject Headings (MeSH) were used: scoliosis, physical therapy modalities, exercise, and conservative treatment, and their combination, depending on the search engine, together with the Boolean operators AND and OR. Articles mentioned in the bibliography of main articles were also reviewed so as not to overlook potentially relevant studies.

\section{Article identification}

Two independent reviewers applied the eligibility criteria to select potentially relevant studies based on the titles and abstracts of articles found after searching the different databases mentioned above. A consensus was established for article inclusion. Then, the full texts of studies that met the eligibility criteria were retrieved. Data were collected in the same manner by two independent reviewers. The author and year of publication, sample size, participants' age, intervention, symptoms, Cobb's angle, neck slope angle, trunk rotation, body asymmetries, functional capacity, muscle endurance, pulmonary function, and outcomes of each study were recorded. A third reviewer cleared up any doubts or disagreement that may have arisen while selecting studies.

\section{Assessment of methodological quality}

Likewise, two independent persons assessed the methodological quality of the CCTs included using the PEDro scale (Table 1), which assessed the methodological quality of studies, considering that studies were of high quality if they scored 6-10, of moderate quality if they scored $4-5$, and of low quality if they scored $0-3,{ }^{20}$ and the levels of evidence of the Oxford Centre of EvidenceBased Medicine (OCEBM) (Table 2), a criterion for harmonization recommended by the SOSORT. ${ }^{18}$

\section{RESULTS}

\section{Study selection}

A total of 1206 articles were retrieved from the different analyzed databases; finally, 15 were considered for a detailed review. Among these, $1^{21}$ was excluded because the sample was not diagnosed with AIS; $2,{ }^{22,23}$ because bracing was used in the intervention group; $2,^{24,25}$ because they were not based on therapeutic exercise; and $1,{ }^{26}$ because it was not a CCT. Finally, a total of 9 clinical trials were included for analysis. The article selection process is shown in a flow chart (Figure 1).

\section{Study characteristics}

All articles corresponded to CCTs written in English. In relation to the range of years of publication, the oldest article was from 2012 and 
the latest, from 2017. The sample size ranged from 24 to 110 participants. All samples from included CCTs totaled 459 patients, divided into 2 groups, except for a study that had 3 groups ${ }^{27}$ All subjects included in the groups were diagnosed with AIS and were in the pediatric age range.

All included studies had corrective, therapeutic exercise as the independent outcome measure; 4 referred to it as Schroth exercises, ${ }^{27-30}$ and the other 5 used different terms that covered therapeutic exercise based on self-correction and spinal stabilization. ${ }^{31-35}$ The intervention period varied greatly: 3 studies included an intervention that lasted 8-12 weeks, ${ }^{30,32,35}$ while 4 conducted interventions for 6 months, ${ }^{27-29-33}$ and 2, for 1 year. ${ }^{31,34}$
In relation to dependent outcome measures, 6 studies assessed symptoms using the following questionnaires: Scoliosis Research Society 22 (SRS-22), ${ }^{28,34}$ Scoliosis Research Society 23 (SRS23), ${ }^{27}$ Numeric Pain Rating Scale (NPRS), ${ }^{32,33}$ and Functional Rating Index (FRI). ${ }^{35}$

Six studies assessed postural parameters, such as Cobb's angle, measured using anteriorposterior X-rays of the trunk with the patient standing, ${ }^{27,29-31,34}$ neck slope angle, measured using a sagittal photogrammetry with the patient sitting down, ${ }^{35}$ angle of trunk rotation, measured using an inclinometry ${ }^{27,34}$ and/or body asymmetries, measured using stereographic projections ${ }^{35}$ or a rigid ruler. ${ }^{27}$

\section{TABle 1. Physiotherapy Evidence Database (PEDro scale)}

1. Eligibility criteria were specified.

2. Subjects were randomly allocated to groups (in a crossover study, subjects were andomly allocated as treatments were administered).

3. Allocation was concealed.

4. The groups were similar at baseline regarding the most important prognostic indicators.

5. There was blinding of all subjects.

6. There was blinding of all therapists who administered the therapy.

7. There was blinding of all assessors who measured at least one key outcome.

8. Measures of at least one key outcome were obtained from more than $85 \%$ of the subjects initially allocated to groups.

9. All subjects for whom outcome measures were available received the treatment or control condition as allocated or, where this was not the case, data for at least one key outcome was analyzed by "intention to treat".

10. The results of between-group statistical comparisons are reported for at least one key outcome.

11. The study provides both point measures and measures of variability for at least one key outcome.

$\begin{array}{lll}\text { No } \square & \text { Yes } \square & \text { Where: } \\ \text { No } \square & \text { Yes } \square & \text { Where: } \\ \text { No } \square & \text { Yes } \square & \text { Where: } \\ \text { No } \square & \text { Yes } \square & \text { Where: } \\ \text { No } \square & \text { Yes } \square & \text { Where: } \\ \text { No } \square & \text { Yes } \square & \text { Where: } \\ \text { No } \square & \text { Yes } \square & \text { Where: } \\ \text { No } \square & \text { Yes } \square & \text { Where: } \\ \text { No } \square & \text { Yes } \square & \text { Where: } \\ \text { No } \square & \text { Yes } \square & \text { Where: } \\ \text { No } \square & \text { Yes } \square & \text { Where: }\end{array}$

TABLE 2. Oxford Centre for Evidence-based Medicine - levels of evidence

\begin{tabular}{|c|c|c|}
\hline Level of recommendation & Level of evidence & Treatment studies \\
\hline \multirow[t]{3}{*}{$\mathrm{A}$} & 1.a & $\begin{array}{l}\text { SR with homogeneity of randomized controlled clinical } \\
\text { trials. }\end{array}$ \\
\hline & 1.b & Individual CT with narrow confidence interval. \\
\hline & 1.c & $\begin{array}{l}\text { Efficiency demonstrated by clinical practice. Considered } \\
\text { when some patients die before the assessment. }\end{array}$ \\
\hline \multirow[t]{5}{*}{ B } & 2.a & SR with homogeneity of cohort studies. \\
\hline & 2.b & $\begin{array}{l}\text { Individual cohort study with }<80 \% \text { of follow-up (including } \\
\text { low-quality CTs). }\end{array}$ \\
\hline & 2.c & Ecological studies or health outcomes research. \\
\hline & 3.a & SR with homogeneity of case-control studies. \\
\hline & 3.b & Individual case-control studies. \\
\hline $\mathrm{C}$ & 4 & $\begin{array}{l}\text { Case-series and poor quality cohort and case-control } \\
\text { studies. }\end{array}$ \\
\hline $\mathrm{D}$ & 5 & $\begin{array}{l}\text { Expert opinion without explicit critical appraisal, or based } \\
\text { on physiology or research work. }\end{array}$ \\
\hline
\end{tabular}

SR: systematic review. CT: clinical trial. 
Six studies assessed the functional capacity of included subjects using the following questionnaires: SRS-22, ${ }^{28,34}$ SRS-23, ${ }^{27}$ Oswestry Low Back Pain Disability Questionnaire (OSW), Patient-Specific Functional Scale (PSFS), ${ }^{32,33}$ and FRI. ${ }^{35}$

In relation to muscle endurance, 2 studies assessed back extensor muscle endurance using the Prone-Double-Leg-Raise Test (PDLRT) ${ }^{32}$ and the Biering-Sorensen test (BME, back muscle endurance). ${ }^{28}$

Two studies assessed the overall perception following the intervention using the Global Rating of Change (GROC). ${ }^{32,33}$

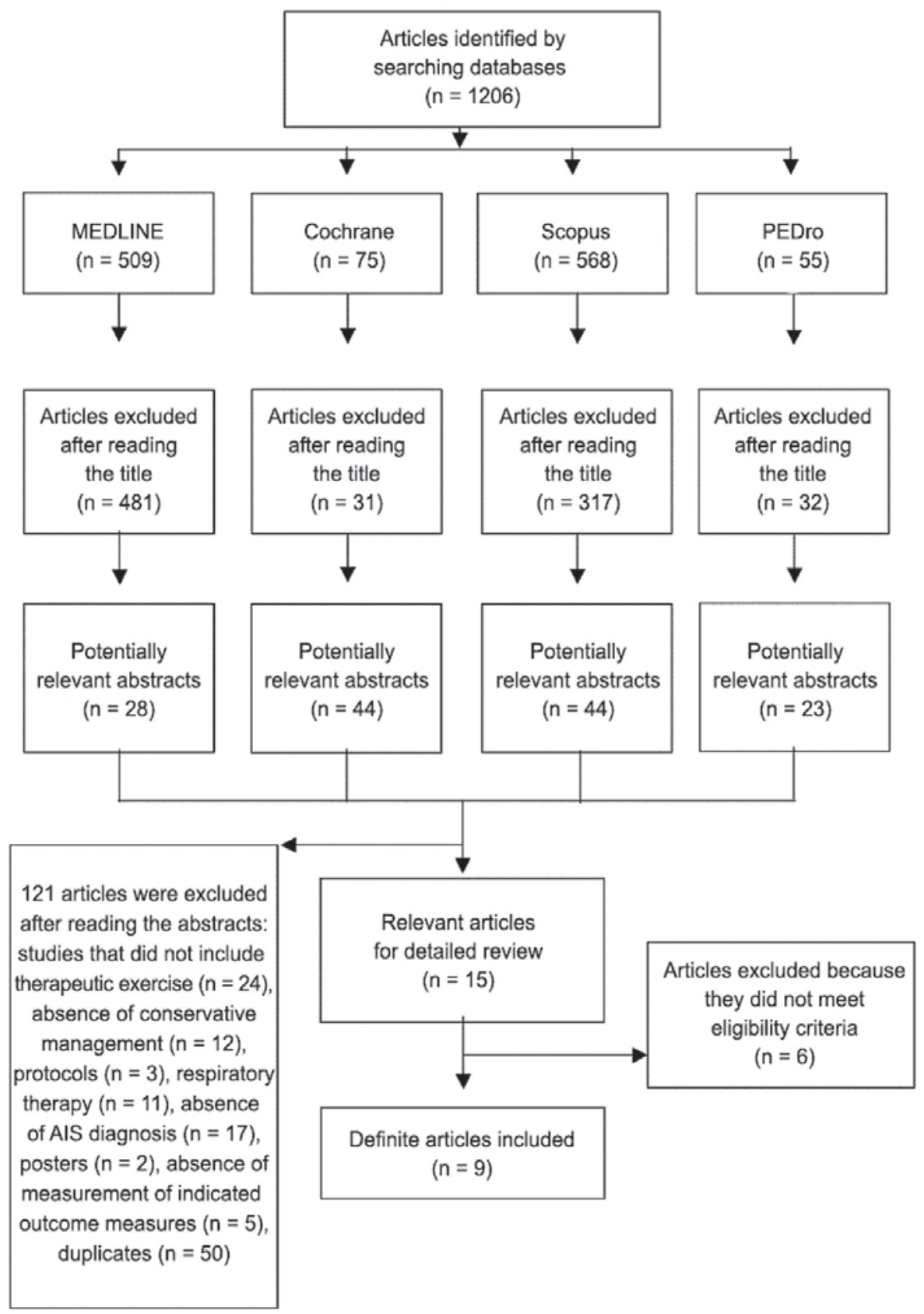

AIS: adolescent idiopathic scoliosis. 
Only 1 study assessed pulmonary function using pulmonary function tests that measured vital capacity (VC), peak expiratory flow (PEF), forced expiratory volume in 1 second $\left(\mathrm{FEV}_{1}\right)$, forced vital capacity (FVC), and the $\mathrm{FEV}_{1} / \mathrm{FVC}_{\text {ratio. }}{ }^{31}$

\section{Methodological quality of included studies}

Eight of the studies scored 6 or more in the PEDro scale, i.e., had a high quality. Two studies scored 5, which means a moderate quality. Some aspects left room for improvement, such as the lack of patient and observer blinding or the failure to submit results for all study subjects. The detailed PEDro scale scoring is shown in Table 3.

All studies showed a level of evidence $1 b,{ }^{36}$ which corresponded to an advisable level of recommendation, moderate evidence that the measure was effective and that the benefits were higher than the detriments, as established by randomized clinical trials with a very low risk for bias.

\section{Therapeutic effectiveness}

The results for each dependent outcome measure obtained after each treatment implemented in the clinical trials included in this review are shown in detail in Table 4.

\section{DISCUSSION}

The objective of this review was to determine the effects of corrective, therapeutic exercise on patients diagnosed with AIS.

The outcomes described in included articles showed that therapeutic exercise had been effective to reduce symptoms, Cobb's angle, craniovertebral angle, trunk rotation, and body asymmetries, and to improve muscular endurance, pulmonary function, and functional capacity of patients with AIS. ${ }^{27-35}$

AIS symptoms are frequently associated with tumors, inflammation or visceral dysfunction; this would exclude solely conservative management. The studies encompassed by this review did not include that type of patients and, after the intervention, they showed a reduction in symptoms. The bibliography is not unanimous about how AIS symptoms start. ${ }^{6}$ Some authors have attributed them to the asymmetric burden that causes early intervertebral disc and facet degeneration and shortening of the muscles. ${ }^{6,37,38}$ However, the mechanism that leads to the improvement in such outcome measure is not known accurately, given that it may be the result of an improved flexibility in the spine and adjacent tissues ${ }^{39}$ or the release of pain modulatory substances resulting from exercise itself. $^{40}$

An article described improvements in pulmonary capacity ${ }^{31}$ Respiratory alterations are more frequent as the Cobb's angle increases; ${ }^{41}$ therefore, bracing -or even surgery- would be recommended for these patients. ${ }^{1}$ However, this information should be taken with caution because it has only been observed in 1 study.

Another finding observed in included articles is the improvement in postural outcome measures. The fact that an effect occurred on selfcorrection and postural control may have helped to stretch tissues on the concave side and modify tissue tension on the convex side of scoliosis. In addition, a key aspect of understanding the biomechanics of these exercises is the activation of the muscles involved in spinal stabilization, such as the multifidus muscle, the rotator group, and the transverse abdominal muscle, etc., which would help to improve postural balance and muscle function; improvements in muscular endurance tests may also be related to this. ${ }^{42,43}$

Findings, collectively, show an improved posture that lies in the ability to maintain self-

TABLE 3. Methodological quality. PEDro scale score

\begin{tabular}{|c|c|c|c|c|c|c|c|c|c|c|c|}
\hline Article & 1 & 2 & 3 & 4 & 5 & 6 & 7 & 8 & 9 & 10 & TOTAL \\
\hline Diab et al., 2012 & Yes & Yes & Yes & No & No & No & Yes & Yes & Yes & Yes & $7 / 10$ \\
\hline Monticone et al., 2014 & Yes & Yes & Yes & Yes & No & Yes & Yes & No & Yes & Yes & $8 / 10$ \\
\hline Zapata et al., 2015 & Yes & No & Yes & No & No & Yes & No & No & Yes & Yes & $5 / 10$ \\
\hline Schreiber et al., 2015 & Yes & Yes & Yes & No & No & Yes & Yes & Yes & Yes & Yes & $8 / 10$ \\
\hline Kuru et al., 2016 & Yes & Yes & Yes & No & No & No & Yes & No & Yes & Yes & $6 / 10$ \\
\hline Schreiber et al., 2016 & Yes & Yes & Yes & No & No & Yes & Yes & Yes & Yes & Yes & $8 / 10$ \\
\hline Kim et al., 2016 & Yes & No & Yes & No & No & No & Yes & Yes & Yes & Yes & $6 / 10$ \\
\hline Zapata et al., 2017 & Yes & No & Yes & No & No & Yes & No & No & Yes & Yes & $5 / 10$ \\
\hline Kumar et al., 2017 & Yes & Yes & Yes & No & No & Yes & Yes & Yes & Yes & Yes & $8 / 10$ \\
\hline
\end{tabular}


correction and postural control over time. Previous studies have supported the benefits of therapeutic exercise by demonstrating that corrective exercises may prevent progression of the curvature ${ }^{14}$ and may even avoid bracing ${ }^{11}$ and surgery. ${ }^{44}$

The improvements in functional capacity and quality of life observed after therapeutic exercise in patients with AIS may be attributed to a reduction in symptoms which, together with better postural parameters, may have influenced patients' self-image and personal satisfaction.

In relation to the number of weekly sessions, a controversial aspect in other research studies, ${ }^{45}$ there is no uniform criterion regarding the number or duration of sessions; in addition, some studies considered both in-person and remote sessions. It is worth noting that the learning and control abilities vary from one subject to another; therefore, it is difficult to estimate the intensity and duration of interventions.

This study does not assess the combined

TABLE 4. Summary of results

\begin{tabular}{|c|c|c|c|c|c|}
\hline Author & $\mathbf{N}$ & $\begin{array}{l}\text { Age (years) } \\
\text { Mean } \pm \text { SD }\end{array}$ & Intervention & Outcome measures & Results \\
\hline \multirow[t]{2}{*}{ Diab et al., 2012} & G1: 38 & $13.2 \pm 1.2$ & G1: control group & \multirow{2}{*}{$\begin{array}{l}\text { Craniovertebral angle, trunk } \\
\text { inclination, lordosis, kyphosis, } \\
\text { imbalance, lateral deviation, pelvic } \\
\text { torsion and rotation FRI }\end{array}$} & $\begin{array}{l}\text { G1-G2: } p<0.05 \text {; improvement } \\
\text { in G2 after } 10 \text { weeks and } 3 \text { months }\end{array}$ \\
\hline & G2: 38 & $14.5 \pm 1.3$ & $\begin{array}{c}\text { G2: postural } \\
\text { self-correction group }\end{array}$ & & $\begin{array}{l}\text { G1-G2: } p<0.05 \text {; improvement } \\
\text { in G2 after } 3 \text { months }\end{array}$ \\
\hline \multirow[t]{2}{*}{ Monticone et al., 2014} & G1: 55 & $12.5 \pm 1.1$ & G1: control group & \multirow[t]{2}{*}{ Cobb's angle, TRA, SRS-22 } & $\begin{array}{l}\text { G1-G2: } p<0.001 \text {; improvement } \\
\text { in G2 after treatment and after }\end{array}$ \\
\hline & G2: 55 & $12.4 \pm 1.1$ & G2: stabilization group & & 12 months \\
\hline \multirow[t]{2}{*}{ Zapata et al., 2015} & G1: 17 & $15.7 \pm 2.0$ & G1: stabilization group & \multirow[t]{2}{*}{ NPRS, PSFS } & $\begin{array}{l}\text { G1-G2: } p<0.05 \text {; improvement } \\
\text { in G1 after } 8 \text { weeks }\end{array}$ \\
\hline & G2: 17 & $14.1 \pm 2.0$ & $\begin{array}{l}\text { G2: uncontrolled } \\
\text { stabilization group }\end{array}$ & & $\begin{array}{l}\mathrm{G} 1: p=0.001 / \mathrm{G} 2: p=0.001 \\
\mathrm{G} 1: p=0.001 / \mathrm{G} 2: p=0.001\end{array}$ \\
\hline \multirow[t]{2}{*}{ Schreiber et al.,2015 } & G1: 25 & $12.7 \pm 1.5$ & G1: control group & BME test & $\begin{array}{l}\text { G1-G2: } p=0.04 \text {; improvement } \\
\text { in G2 after } 3 \text { months }\end{array}$ \\
\hline & G2: 25 & $12.7 \pm 1.2$ & $\begin{array}{l}\text { G2: Schroth } \\
\text { exercise group }\end{array}$ & SRS-22 & $\begin{array}{l}\text { G1-G2: } p<0.05 \text {; improvement } \\
\text { in symptoms and function of } \\
\text { G2 after } 3 \text { months }\end{array}$ \\
\hline \multirow[t]{3}{*}{ Kuru et al., 2016} & G1: 15 & $12.9 \pm 1.4$ & G1: Schroth exercise group & \multirow{3}{*}{$\begin{array}{l}\text { Cobb's angle } \\
\text { Rotation angle, hump height, } \\
\text { waist asymmetry }\end{array}$} & $\begin{array}{l}\text { G1-G2-G3: } p=0.003 \text {; improvement } \\
\text { in G1 after } 24 \text { weeks }\end{array}$ \\
\hline & G2: 15 & $13.1 \pm 1.7$ & $\begin{array}{l}\text { G2: uncontrolled Schroth } \\
\text { exercise group }\end{array}$ & & $\begin{array}{l}\text { G1-G2-G3: } p<0.01 \text {;improvement } \\
\text { in G1 after } 6 \text { and } 24 \text { weeks }\end{array}$ \\
\hline & G3: 15 & $12.8 \pm 1.2$ & G3: control & & \\
\hline \multirow[t]{2}{*}{ Schreiber et al., 2016} & G1: 25 & $13.5(12.7-14.2)$ & G1: Schroth exercise group & Major curve & $\begin{array}{l}\text { G1-G2: } p=0.006 \text {; improvement } \\
\text { in G1 after } 6 \text { months }\end{array}$ \\
\hline & G2: 25 & $13.3(12.7-13.9)$ & G2: control group & Sum of curves & $\begin{array}{l}\text { G1-G2: } p=0.048 \text {; improvement } \\
\text { in G1 after } 6 \text { months }\end{array}$ \\
\hline \multirow[t]{2}{*}{ Kim et al., 2016} & G1: 12 & $15.3 \pm 0.8$ & G1: Schroth exercise group & \multirow{2}{*}{$\begin{array}{l}\text { Cobb's angle, weight distribution } \\
\text { between the concave and convex } \\
\text { sides }\end{array}$} & \multirow[t]{2}{*}{$\begin{array}{l}\text { G1-G2: } p<0.05 \text {; improvement } \\
\text { in G1 after } 12 \text { weeks }\end{array}$} \\
\hline & G2: 12 & $15.6 \pm 1.1$ & G2: Pilates group & & \\
\hline \multirow[t]{2}{*}{ Zapata et al., 2017} & G1: 17 & $15.5 \pm 2.2$ & G1: stabilization group & NPRS and GROC & $\begin{array}{l}\text { G1-G2: } p<0.05 \text {; improvement } \\
\text { in G1 after } 6 \text { months }\end{array}$ \\
\hline & G2: 17 & $14.0 \pm 2.0$ & $\begin{array}{l}\text { G2: uncontrolled } \\
\text { stabilization group }\end{array}$ & OSW and PSFS & $\mathrm{G} 1: p<0.001 / \mathrm{G} 2: p<0.001$ \\
\hline \multirow[t]{2}{*}{ Kumar et al., 2017} & G1: 18 & $12.1 \pm 1.7$ & G1: control group & Cobb's angle, FVC, FEV1, VC & \multirow[t]{2}{*}{$\begin{array}{l}\text { G1-G2: } p<0.001 \text {; improvement } \\
\text { in G2 after } 1 \text { year }\end{array}$} \\
\hline & G2: 18 & $11.5 \pm 1.4$ & $\begin{array}{c}\text { G2: postural } \\
\text { self-correction group }\end{array}$ & PEF & \\
\hline
\end{tabular}

G: group; p: statistical value; TRA: trunk rotation angle; BME: back muscle endurance; FEV1: forced expiratory volume in 1 second; FRI: Functional Rating Index; FVC: forced vital capacity; GROC: Global Rating of Change; NPRS: Numeric Pain Rating Scale; OSW: Oswestry Low Back Pain Disability Questionnaire (revised); PDLRT: Prone-Double-Leg-Raise Test; PEF: peak expiratory flow; PSFS: Patient-Specific Functional Scale; SRS-22r: Scoliosis Research Society Patient Outcomes questionnaire 22r;

SRS-23: Scoliosis Research Society Patient Outcomes questionnaire 23; VC: vital capacity. 
effects of bracing and therapeutic exercise; it is considered that, in clinical practice, not only one isolated technique is used, and the latter works as an adjuvant measure for the management of AIS.

\section{LIMITATIONS}

One of the main limitations was the small number of articles included, which indicates that there is little evidence on the use of therapeutic exercise for the management of this disease.

In addition, some articles failed to describe the methodology appropriately, thus hindering the assessment of methodological quality. All articles left room for improvement in terms of methodological aspects, and it is worth noting the lack of patient and observer blinding and the failure to submit results for all study subjects.

As recommended in the 2014 consensus between the SOSORT and the SRS, ${ }^{18}$ the different tools used to measure dependent outcome measures hamper study comparison.

In addition, the low methodological quality of some studies prevented us from including certain exercise techniques, such as global postural reeducation and the Klapp method, which, in clinical practice, are used in these patients.

\section{CONCLUSION}

The results of this review appear to point out the positive effects of AIS management with therapeutic exercise based on the Schroth method or stabilization exercises. Therapeutic exercise reduces symptoms and improves function, vertebral angles, and trunk asymmetries. It is not possible to describe the ideal moment for the intervention or the number of weekly sessions and the duration of each session. Therefore, further studies are necessary with a better methodological quality on therapeutic exercise that measure clinical and imaging outcome measures to obtain conclusive results.

\section{REFERENCES}

1. Gacitúa MV, González MC, Sanz C, et al. Consenso de escoliosis idiopática del adolescente. Arch Argent Pediatr 2016; 114(6):585-94.

2. Chin KR, Price JS, Zimbler S. A guide to early detection of scoliosis. Contemp Pediatr 2001; 18(9):77-103.

3. Schlösser TP, van der Heijden GJ, Versteeg AL, et al. How "idiopathic" is adolescent idiopathic scoliosis? A systematic review on associated abnormalities. PLoS One 2014; 9(5):e97561.

4. Reamy BV, Slakey J. Adolescent Idiopatic Scoliosis: Review and Current Concepts. Am Fam Physician 2001; 64(1):111-6.

5. Sato T, Hirano T, Ito T, et al. Back pain in adolescents with idiopathic scoliosis: epidemiological study for 43,630 pupils in Niigata City, Japan. Eur Spine J 2011; 20(2):274-9.
6. Gotfryd AO, Franzin FJ, Poletto PR, et al. Pain assessment in patients with adolescent idiopathic scoliosis at different stages of disease evolution. Medical Express (São Paulo. Online) 2014; 1(4):170-3.

7. Theroux J, Le May S, Fortin C, et al. Prevalence and management of back pain in adolescent idiopathic scoliosis patients: A retrospective study. Pain Res Manag 2015; 20(3):153-7.

8. Martínez-Llorens J, Ramírez M, Colomina MJ, et al. Muscle dysfunction and exercise limitation in adolescentidiopathic scoliosis. Eur Respir J 2010; 36(2):393-400.

9. Trobisch P, Suess O, Schwab F. Idiopathic scoliosis. Dtsch Arztebl Int 2010; 107(49):875-83.

10. Berdishevsky H, Lebel VA, Bettany-Saltikov J, et al. Physiotherapy scoliosis-specific exercises - a comprehensive review of seven major schools. Scoliosis Spinal Disord 2016; 11:20.

11. Negrini S, Zaina F, Romano M, et al. Specific exercises reduce brace prescription in adolescent idiopathic scoliosis: A prospective controlled cohort study with worst-case analysis. J Rehabil Med 2008; 40(6):451-5.

12. Fusco C, Zaina F, Atanasio S, et al. Physical exercises in the treatment of adolescent idiopathic scoliosis: an updated systematic review. Physiother Theory Pract 2011; 27(1):80114.

13. YangJM, LeeJH, LeeDH. Effects of consecutive application of stretching, Schroth, and strengthening exercises on Cobb's angle and the rib hump in an adult with idiopathic scoliosis. J Phys Ther Sci 2015; 27(8):2667-9.

14. Negrini S, Fusco C, Minozzi S, et al. Exercises reduce the progression rate of adolescent idiopathic scoliosis: results of a comprehensive systematic review of the literature. Disabil Rehabil 2008; 30(10):772-85.

15. Weiss HR, Moramarco MM, Borysov M, et al. Postural rehabilitation for adolescent idiopathic scoliosis during growth. Asian Spine J 2016; 10(3):570-81.

16. Negrini S, Aulisa AG, Aulisa L, et al. 2011 SOSORT guidelines: Orthopaedic and Rehabilitation treatment of idiopathic scoliosis during growth. Scoliosis 2012; 7(1):3.

17. Moher D, Shamseer L, Clarke M, et al. Preferred reporting items for systematic review and meta-analysis protocols (PRISMA-P) 2015 statement. Syst Rev 2015; 4(1):1.

18. Negrini S, Hresko TM, O'Brien JP, et al. Recommendations for research studies on treatment of idiopathic scoliosis: Consensus 2014 between SOSORT and SRS non-operative management committee. Scoliosis 2015; 10(1):8.

19. Asociación Española de Pediatría de Atención Primaria. Pediatría en Europa: organización y formación. [Accessed on: February $\left.20^{\text {th }}, 2018\right]$. Available at: https: / / www.aepap. org/grupos / grupo-de-relaciones-con-pediatria-europea/ pediatria-en-europa.

20. Ajimsha MS, Al-Mudahka NR, Al-Madzhar JA. Effectiveness of myofascial release: Systematic review of randomized controlled trials. J Bodyw Mov Ther 2015; 19(1):102-12.

21. Dantas DS, De Assis S, Baroni M, et al. Klapp method effect on idiopathic scoliosis in adolescents: blind randomized controlled clinical trial. J Phys Ther Sci 2017; 29(1):1-7.

22. Gür G, Ayhan C, Yakut Y. The effectiveness of core stabilization exercise in adolescent idiopathic scoliosis: A randomized controlled trial. Prosthet Orthot Int 2017;41(3):303-10.

23. Plewka B, Sibinski M,Synder M, et al. Clinical assessment of the efficacy of SpineCor brace in the correction of postural deformities in the course of idiopathic scoliosis. Pol Orthop Traumatol 2013; 78:85-9.

24. Weiss H-R, Hollaender M, Klein R. ADL based scoliosis rehabilitation--the key to an improvement of time- 
efficiency? Stud Health Technol Inform 2006; 123:594-8.

25. Lapuente JP, Sastre S, Barrios C. Idiopathic scoliosis under 30 degrees in growing patients. A comparative study of the F.E.D. method and other conservative treatments. Stud Health Technol Inform 2002; 88:258-69.

26. Rigo M, Quera-Salvá G, Villagrasa M, et al. Scoliosis intensive out-patient rehabilitation based on Schroth method. Stud Health Technol Inform 2008; 135:208-27.

27. Kuru T, Yeldan I, Dereli EE, et al. The efficacy of threedimensional Schroth exercises in adolescent idiopathic scoliosis: a randomised controlled clinical trial. Clin Rehabil 2016; 30(2):181-90.

28. Schreiber S, Parent EC, Moez EK, et al. The effect of Schroth exercises added to the standard of care on the quality of life and muscle endurance in adolescents with idiopathic scoliosis—an assessor and statistician blinded randomized controlled trial: "SOSORT 2015 Award Winner." Scoliosis 2015; 10(1):24.

29. Schreiber S, Parent EC, Moez EK, et al. Schroth Physiotherapeutic Scoliosis-Specific Exercises Added to the Standard of Care Lead to Better Cobb Angle Outcomes in Adolescents with Idiopathic Scoliosis - an Assessor and Statistician Blinded Randomized Controlled Trial. PLoS One 2016; 11(12):e0168746.

30. Kim G,HwangBo P. Effects of Schroth and Pilates exercises on the Cobb angle and weight distribution of patients with scoliosis. J Phys Ther Sci 2016; 28(3):1012-5.

31. Kumar A, Kumar S, Sharma V, et al. Efficacy of Task Oriented Exercise Program Based on Ergonomics on Cobb's Angle and Pulmonary Function Improvement in Adolescent Idiopathic Scoliosis- A Randomized Control Trial. J Clin Diagnostic Res 2017; 11(8):1-4.

32. Zapata KA, Wang-Price SS, Sucato DJ, et al. Spinal Stabilization Exercise Effectiveness for Low Back Pain in Adolescent Idiopathic Scoliosis. Pediatr Phys Ther 2015; 27(4):396-402.

33. Zapata KA, Wang-Price SS, Sucato DJ. Six-Month Followup of Supervised Spinal Stabilization Exercises for Low Back Pain in Adolescent Idiopathic Scoliosis. Pediatr Phys Ther 2017; 29(1):62-6.

34. Monticone M, Ambrosini E, Cazzaniga D, et al. Active self-correction and task-oriented exercises reduce spinal deformity and improve quality of life in subjects with mild adolescent idiopathic scoliosis. Results of a randomized controlled trial. Eur Spine J 2014; 23(6):1204-14.

35. Diab AA. The role of forward head correction in management of adolescent idiopathic scoliotic patients: a randomized controlled trial. Clin Rehabil 2012; 26(12):1123-32.

36. Marzo-Castillejo M, Viana-Zulaica C. Calidad de la evidencia y grado de recomendación. Guias Clilnicas 2007; 7(Supl 1):6.

37. Danielsson AJ, Romberg K, Nachemson AL. Spinal Range of Motion, Muscle Endurance, and Back Pain and Function at Least 20 Years After Fusion or Brace Treatment for Adolescent Idiopathic Scoliosis: a case-control study. Spine (Phila Pa 1976) 2006; 31(3):275-83.

38. Bunnell WP. Thenatural history of idiopathicscoliosis before skeletal maturity. Spine (Phila Pa 1976) 1986; 11(8):773-6.

39. Smorgick Y, Mirovsky Y, Baker KC, et al. Predictors of back pain in adolescent idiopathic scoliosis surgical candidates. J Pediatr Orthop 2013; 33(3):289-92.

40. Louw A, Diener I, Butler DS, et al. The effect of neuroscience education on pain, disability, anxiety, and stress in chronic musculoskeletal pain. Arch Phys Med Rehabil 2011; 92(12):2041-56.

41. Dos Santos Alves VL, Stirbulov R, Avanzi O. Impact of a physical rehabilitation program on the respiratory function of adolescents with idiopathic scoliosis. Chest 2006; 130(2):500-5.

42. Koumantakis GA, Watson PJ, Oldham JA. Trunk muscle stabilization training plus general exercise versus general exercise only: randomized controlled trial of patients with recurrent low back pain. Phys Ther 2005; 85(3):209-25.

43. Koumantakis GA, Watson PJ, OldhamJA.Supplementation of general endurance exercise with stabilisation training versus general exercise only. Physiological and functional outcomes of a randomised controlled trial of patients with recurrent low back pain. Clin Biomech (Bristol, Avon) 2005; 20(5):474-82.

44. Hawes MC. The use of exercises in the treatment of scoliosis: An evidence-based critical review of the literature. Pediatr Rehabil 2003; 6(3-4):171-82.

45. Negrini A, Verzini N, ParziniS, et al. Role of physical exercise in the tratment of mild idiopathic adolescent scoliosis. Eur Med Phis 2001; 37(3):181-90. 